\title{
CRYPTOCOCCOSIS OF THE NERVOUS SYSTEM
}

\author{
R. P. JaYewardene, M.D., M.R.C.P. \\ W. B. Wijekoon, M.B., B.S. \\ From the Department of Medicine, University of Ceylon, Colombo
}

Cryptococcosis (torulosis) is a fungus disease caused by the Cryptococcus neoformans (Torula histolytica). It appears to be most common in the United States (Littman and Zimmerman, 1956) and in Australia (Cox and Tolhurst, 1946). Over 300 cases have now been reported in the world literature.

This is a report of the first case of Cryptococcus infection diagnosed and confirmed in Ceylon.

\section{Case Report}

A male, age 45 years, resident in Colombo, was admitted to hospital on 7.9.6I complaining of headache, fever and vomiting of I4 days' duration. The headache preceded the fever and vomiting by ten days. Three years previously he was treated at the Chest Hospital for one month. No details of this illness are available. There were no other illnesses of note.

On Examination: Temp. $100^{\circ} \mathrm{F}$., the tongue was dry and coated, and the throat and tonsils normal. There were no carious teeth. There was no oedema of the feet. There were a few patches of tinea versicolor on the left upper arm. The skin was otherwise healthy. There were no enlarged lymph glands. The cardiovascular, respiratory and gastrointestinal systems were clinically normal. The ocular fundi were normal and the nervous system was apparently normal.

Investigations: $\mathrm{Hb} 75 \%$, w.b.c. $10,200 / \mathrm{cu} . \mathrm{mm}$., polys $79 \%$, lymphs $15 \%$, eosinos $2 \%$, monos $4 \%$, ESR $5 \mathrm{~mm}$./hour. Urine: Bile nil, albumin + , epithelial cells + . S.A.T. negative, Mantoux negative. Blood urea $48 \mathrm{mg}$. $/ 100 \mathrm{ml}$. Blood culture sterile. Chest $\mathrm{X}$-ray: slight emphysema. The temperature was remittent and headache severe. On the sixth day there was neck rigidity and Kernig's sign was present. Lumbar puncture was done. The CSF was under tension and opalescent and contained protein $80 \mathrm{mg} . /$ roo ml., chlorides $644 \mathrm{mg}$./ $100 \mathrm{ml}$., sugar $34 \mathrm{mg}$./ $100 \mathrm{ml}$., r.b.c. $3 /$ cu. $\mathrm{mm}$., w.b.c. $\mathrm{r} 60 /$ cu. $\mathrm{mm}$. (lymphocytes ++ ). The Wasserman and Kahn reactions were negative in blood and CSF.

Progress: Treatment for tuberculous meningitis was started at once and fluid balance maintained by intravenous fluids, when vomiting was severe. The fever, headache and vomiting persisted. Five days later the CSF showed protein $65 \mathrm{mg}$./100 $\mathrm{ml}$., chlorides $632 \mathrm{mg}$. $/ 100 \mathrm{ml}$., sugar $67 \mathrm{mg}$. $/$ I $00 \mathrm{ml}$., r.b.c. $5 / \mathrm{cu} . \mathrm{mm}$., w.b.c. II5/cu. mm. (lymphocytes ++ ), X-ray of the skull showed some opacity of the antra. Since there was no response to the anti-tuberculous drugs, and the CSF showed almost no change except for the increase of cells, the possibility of a fungus infection was considered and the CSF sent for examination for yeast cells and for culture. The report on the CSF was as follows:-Yeast cells ++ , Indian ink stain showed capsulated and budding yeast cells $+($ Fig. $\mathbf{r})$.

On the next day the temperature was normal but the patient was drowsy and complained of severe headache. Vomiting was more frequent. Photophobia was now present and ptosis of the right eye was noted. The pupil on the right side was larger and the reaction to

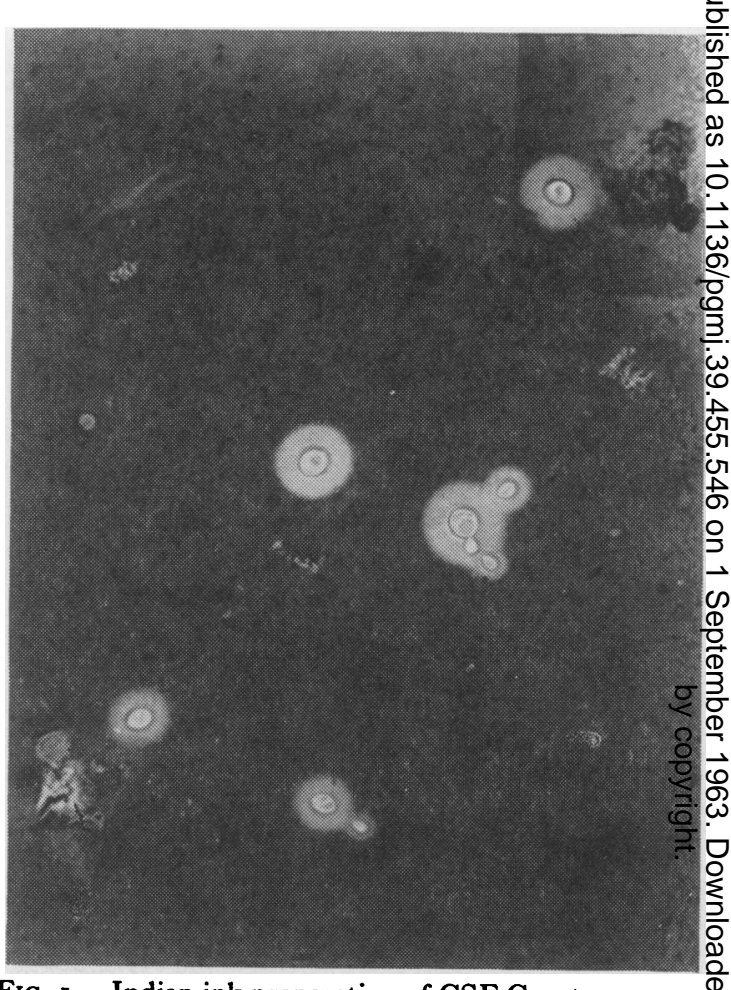

FIG. r.-Indian ink preparation of CSF Cryptococcus $-\frac{\mathbb{Q}}{\Omega}$ cells showing budding and clear area of capsules.

light was impaired. Neck rigidity and Kernig's sign were now marked. The temperature returned to the former level and remained remittent, and his condition:deteriorated rapidly. Lumbar puncture was done음 every other day to relieve the headache. Every specimen 3 . of the CSF contained the capsulated yeast cells. The patient gradually become more drowsy and lapsed 3 . into a coma and died three weeks after admission too hospital.

Autopsy Report (Dr. G. E. Tennekoon, Department of Pathology). The lungs showed hypostatic conges-O tion. There was a small firm area towards the lower? part of the right upper lobe. Liver showed a few widely scattered miliary whitish areas. Spleen showed four rounded whitish yellow areas 1 to $\mathbf{I} \mathbf{c m}$. in diameter $N$ on the surface. The nodules contained greyish granular caseous material. Kidneys: A few scattered miliary $N$ nodules were present mostly in the cortex. Brain:N The meninges both of the vertex and the base appeared $\omega$ œdematous and gelatinous with a slight degree of whitish grey opacity. On cutting into the brain thereo were several cystic spaces varying in diameter from $1 \mathrm{~mm}$. to about $5 \mathrm{~mm}$. These were mostly in the basal $\cong$ ganglia. They contained a gelatinous material which tended to come off on the knife. 
Histology: The brain, meninges, spleen and kidneys showed the fungus, which appeared as small spheres reproducing by budding. The lesions in the brain were meningeal and perivascular in the basal ganglia. The lesions in the brain and spleen had a minimal tissue reaction. In the liver and kidneys there were miliary collections of histiocytic cells containing the fungus. The firm nodule in the lung showed fibrosis, chronic inflammatory cells and two giant cells. There was no evidence of the fungus. It was not possible to be certain whether this was the primary focus of infection.

\section{Discussion}

Visceral infection by fungi may often be overlooked when there is no obvious skin lesion. In this patient the only possible portals of entry for the fungus could have been either the antrum, the X-ray of which showed an opacity, although there was no clinical evidence or any history of disease, or the lung, which showed evidence of previous disease.

The low antigenicity of most fungi does not lead to an acute inflammatory reaction; even a tissue reaction is slow to develop. When this occurs it is of a slowly developing granulomatous nature with the formation of a foreign-body type of giant cells as the fungus is treated as a foreign body. The presence of cystic spaces in the region of the basal ganglia and the gelatinous exudate of the meninges without acute meningeal inflammation show these aspects of the pathological process. The increase of lymphocytes and the reduction of the chlorides and sugar of the CSF suggested tuberculous meningitis. But the lack of response to streptomycin and the slight alteration of the CSF chlorides and sugar on repeated lumbar puncture offered a clue to the probable cause of the meningitis.

Skin tests, complement fixation and precipitin tests were not done.

Treatment with the specific antibiotic amphotericin B was not possible as the patient succumbed before the drug was obtained from the United States.

The increasing incidence of fungal disease associated with the widespread use of antibiotics may tend to make cryptococcosis more common. The possibility of remission and arrest of the disease with amphotericin B makes it imperative that this disease be kept in mind and looked for before the patient is too ill.

\section{Summary}

A case of disseminated cryptococcosis with meningo-encephalitis is described.

Widespread lesions were revealed only at postmortem.

A short description of the lesions in the brain and viscera is given.

The association of cryptococcosis with reticuloendothelial disease is mentioned.

The importance of early investigation and treatment is stressed.

\title{
REFERENCES
}

Cox, L. B., and Tolnurst, J. C. (1946): 'Human Torulosis'. Melbourne: Melbourne University Press. Littman, M. L., and Zimmerman, L. E. (r956): 'Cryptococcosis.' New York: Grune \& Stratton.

\section{BRONCHIAL ADENOMA WITH THE CARCINOID SYNDROME PRESENTING WITH UNUSUAL SKIN CHANGES}

\author{
H. T. Calvert, M.A., M.B., M.R.C.P. \\ A. J. KarLish, M.D., M.R.C.P. \\ R. S. Wells, M.B., M.R.C.P., M.R.C.P.(Edin.), D.C.H. \\ The Departments of Dermatology and Diseases of the Chest, The Reading Group of Hospitals
}

THE term 'carcinoid' was first introduced by Oberndorfer in 1907 to distinguish certain atypical carcinomas of the bowel from ordinary adenocarcinomas. He gave a good histological description of the tumour and the chromaffin cells of which it was composed and thought it was benign. Carcinoid tumours are found most frequently in the gastrointestinal tract, with an estimated $60 \%$ to $90 \%$ of them in the appendix. They probably form from $0.1 \%$ to $0.5 \%$ of all tumours found at post-mortem and only a small proportion of them give rise to the carcinoid syndrome, which was first described by Thorson, Biorck and Waldenström in 1954.

The clinical and biochemical features of the carcinoid syndrome produced by functioning carcinoid tumours originating in the bronchi have been reported in the last few years; of the 21 patients described, I 9 have been associated with a bronchial adenoma and two with an oat-cell carcinoma. The following is a report of a patient 